\title{
O uso do dicionário como estratégia metacognitiva de aquisição lexical na leitura em mídia virtual e impressa
}

\author{
Dictionary use as a metacognitive strategy for lexical acquisition in the reading process: \\ virtual and printed media
}

\author{
Claudia Finger-Kratochvil ${ }^{1}$, Margarete G. M. de Carvalho²
}

Doutora em Linguística, Psicolinguística, pela Universidade Federal de Santa Catarina, e docente da Universidade Federa da Fronteira Sul, Letras, e no programa de E-mil:

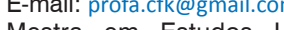
Théric SulEducacionais do E-mail: margarete.carvalho@ifsc.edu.b
RESUMO: Pesquisas vêm comparando os dicionários eletrônicos aos impressos para verificar qual deles responde melhor às demandas do leitor com relação à construção do conhecimento lexical, visando à compreensão leitora. Este artigo apresenta resultados de uma pesquisa pré-experimental psicolinguística, que verificou o desenvolvimento da estratégia do uso do dicionário para aquisição do conhecimento lexical a partir do blog e do material impresso no processo de construção da competência leitora. Participaram professores de Português de escolas públicas de Santa Catarina. Buscamos identificar em qual dos meios o tempo de quebra do fluxo de leitura - devido às pausas para consulta ao dicionário - seria menor, e se essa consulta contribuiria para a compreensão leitora dos participantes, expressa por meio de uma síntese. Os resultados revelaram uma tênue diferença de compreensão leitora entre uma mídia e outra. Isso parece indicar que não é, fundamentalmente, a mídia o fator determinante para diferenças na compreensão nem para o uso de estratégias, ainda que o suporte virtual apresente algumas singularidades que, a princípio, causem estranheza ao leitor mais adaptado ao material impresso. 0 fator mais relevante foi a capacidade, demonstrada pelo leitor, de selecionar a estratégia mais adequada e de decidir utilizá-la ou não.

PaLAvras-chave: Leitura; Competência lexical; Uso do dicionário; Mídia virtual (blog)

ABSTRACT: Different works have been studying the use of printed and electronic dictionaries and their relationship to the construction of lexical knowledge and reading comprehension. Throughout this study, we discuss the results of a pre-experimental research, considering a psycholinguistic approach, in the process of reading comprehension, meaning construction of text, and (the use of) the dictionary skills in the printed and virtual media (blog). Participants were pre-service and in-service teachers of L1, and all of them were in class effectively at public schools in Santa Catarina. Three aspects were observed to understand the processes of reading comprehension: time of each task developed, quality of the reading comprehension (synthesis) and the use of dictionaries offered. One of our aims was to compare and verify whether the interruption in the reading flow could get any advantage of the use of electronic media and electronic dictionaries, and besides that whether readers could have any improvement in their reading comprehension. According to the data, printed or virtual media does not seem to be the crucial factor of differences in the processes studied, but the use of strategies and abilities readers may use in the reading meaning construction.

KEYwORDS: Reading; Lexical competence; Dictionary use; Virtual media (blog) 


\section{Introdução}

fim de colaborar com as investigações sobre a proficiência em leitura, pelo viés da Psicolinguística, e sua relação com as Tecnologias da Informação e da Comunicação - TICs - voltamo-nos para o blog e sua relação com a compreensão leitora, no que se refere à construção da competência lexical a partir do uso do dicionário como estratégia metacognitiva.

No presente artigo $^{1}$, estabelecemos um recorte de nossa pesquisa, observando a interrupção do fluxo de leitura para consulta a dicionários, tanto na mídia impressa quanto na mídia virtual (blog) e seus desdobramentos na e para a compreensão leitora, uma vez que o processo de letramento deve ser estudado como um conjunto de processos e subprocessos que compõem capacidades, habilidades e estratégias relativas à leitura, envolvendo múltiplas linguagens, em um determinado tempo e contexto social (FINGERKRATOCHVIL, 2009).

O tema tem adquirido relevância no contexto brasileiro e despertado o interesse de pesquisadores e educadores no Brasil e no mundo, especialmente nos últimos 15 anos, visto que a qualidade da compreensão leitora dos estudantes, nos diversos níveis de ensino, tem se mostrado frágil no cotidiano da prática escolar. Fragilidade revelada nos índices de avaliações nacionais e internacionais tais como: Inaf, Prova Brasil/Enem, Pisa, e revelada em outros estudos (PEREIRA, 2008; NASCIMENTO, et al., 2011) voltados à prática da leitura e ao desenvolvimento de tarefas que envolvam a compreensão leitora de modo geral. Por consequência, para alguns estudantes essa atividade gera desagrado, frustração, rejeição e desconforto, mesmo que lhes sejam oferecidos gêneros textuais e assuntos mais familiares e/ou de menor complexidade. Essa dificuldade relacionada à

1 Agradecemos à CAPES pelo apoio ao desenvolvimento dessa pesquisa por meio do Edital 0049/2012 do Observatório da Educação: Projeto Ler \& Educar. compreensão leitora tem feito com que a atenção dos governos, educadores e pesquisadores volte-se, nos últimos anos, para os níveis de proficiência em leitura dos indivíduos considerados alfabetizados e escolarizados, e não só para os índices de analfabetismo como acontecia no passado (RIBEIRO, 2006; SCLIAR-CABRAL, 2013).

Ao considerar que as exigências que se colocam aos leitores dos anos 2000 se intensificam com o advento e o dinamismo das Tecnologias da Informação e da Comunicação (TICs), o desafio de ampliar as habilidades de letramento torna-se ainda maior (CASSANY, 2004, AGUILERA, 2010), tendo em vista que, conforme Finger-Kratochvil (2009, p. 207), "em uma sociedade cada vez mais grafocêntrica, o domínio das competências do letramento é sinônimo de inclusão social". Entretanto, com as próprias TICs surgem outras possibilidades de se adquirir as habilidades envolvidas nesse(s) processo(s). Pesquisadores, provocados por questões relativas às práticas leitoras mediadas ou suportadas pelo computador e mais especificamente pela internet, têm investigado como as mídias virtuais podem auxiliar no processo de letramento, visto possibilitarem a leitura a partir de novos modelos (CASSANY, 2004; TOMITCH, 2008; FINGER-KRATOCHVIL, 2010, COSCARELLI, 2010, GOLDMAN et al., 2012). Contudo, para que o nível das habilidades de letramento dos estudantes seja desenvolvido de forma plena, para além do satisfatório, é importante contemplar no processo ensino-aprendizagem uma das competências fundamentais para o sucesso na leitura, i.e., a competência lexical, pois é um dos principais fatores que influenciam na compreensão leitora (FARSTRUP; SAMUELS, 2008; BAUMANN; KAME’ENUI; ASH, 2003).

\section{Conhecimento lexical, compreensão leitora e metacognição}

Diferentes estudos assinalam que, para o desenvolvimento e expansão da habilidade de leitura, o conhecimento do vocabulário é condição 
fundamental, uma vez que os demais processos de aquisição e de conexão das informações estão atrelados a ele. Ao longo de seus trabalhos, Schmitt et al. (2011) constataram que:

Há uma relação linear bastante simples entre o crescimento no conhecimento de vocabulário de um texto e compreensão do texto. Esta relação (com base nos textos e tarefas particulares, neste estudo de avaliação) pode ser caracterizada como um aumento no crescimento da compreensão de $2,3 \%$ por cada $1 \%$ de crescimento no conhecimento de vocabulário (entre $92 \%$ e $100 \%$ de cobertura de vocabulário) (SCHMITT; JIAN e GRABE, 2011- tradução nossa²).

Por essas razões, apesar de sabermos que o domínio completo do léxico de uma língua é algo inatingível devido, especialmente, à existência de muitas áreas de conhecimento específico e à própria natureza das palavras (e.g. polissemia), entendemos que é necessário investir no desenvolvimento de habilidades estratégicas voltadas para a ampliação do léxico (LEFFA, 1996; SCHMITT; JIANG; GRABE, 2011; LIBERATO; FULGÊNCIO, 2012).

A respeito do conhecimento lexical, estudos de Richards (1976), Nagy e Herman (1987) e Nagy e Scott (2013) apontam diferentes aspectos que o compõem. São eles, a amplitude (size) e a profundidade (breadth) do conhecimento, inicialmente entendidos como dimensões que se entrecruzam no processo de construção do conhecimento lexical, e posteriormente, como aspectos do conhecimento complexo e inter-relacionado ligado à palavra. Esse conjunto de conhecimentos diz respeito à quantidade de palavras que um indivíduo adquire e à riqueza das representações mentais construídas que permitem a incorporação constante de novos matizes de significado.

\footnotetext{
2 There is a fairly straightforward linear relationship between growth in vocabulary knowledge for a text and comprehension of that text. This relationship (based on the particular texts and assessment tasks in this study) can be characterized as an increase in comprehension growth of $2.3 \%$ for each $1 \%$ grow vocabulary can be characterized as an increase in comprehension growth of $2.3 \%$ for each $1 \%$ growth in vocabulary knowledge (between $92 \%$ and $100 \%$ of vocabulary coverage) (SCHMIT, N., JIANG, X. and
GRABE, W., 2011).
}

Em outras palavras, o conhecimento das palavras aumenta em número de vocábulos, amplia-se ao longo de toda vida, e esse mesmo conhecimento ganha em profundidade à medida que o indivíduo se depara com outros aspectos de uso e possíveis sentidos dos termos em diferentes contextos (escritos ou falados). Desta forma, a frequência e a colocação sintagmática de uma palavra, as restrições impostas ao seu uso em contextos específicos, suas derivações e relações paradigmáticas possíveis e as acepções associadas a ela são exemplos dos muitos aspectos a serem construídos a respeito do léxico. Possuir um vocabulário amplo, especialmente na educação é muito importante, pois quem tem um vocabulário vasto compreende com mais facilidade o que lê (RANGEL, 2006).

Diante da complexidade envolvida na construção do conhecimento lexical, é imprescindível que, no ensino da leitura, seja observado o aumento das habilidades metacognitivas e metalinguísticas, para que haja ampliação desse conhecimento (FINGER-KRATOCHVIL, 2010). O sujeito que conhece seus recursos cognitivos tem condições de controlar seu próprio conhecimento, planificando, verificando e avaliando seus avanços. Essa capacidade é entendida como parte da metacognição (BAKER e BROWN, 1984).

Processos metacognitivos são compreendidos como aspectos passíveis de serem controlados pelo ser humano. Ao mesmo tempo em que aprende, ele se utiliza de estratégias para monitorar seu aprendizado (automonitoria). Assim, ser instruído a respeito das capacidades metacognitivas permite ao indivíduo saber como se efetiva o conhecimento, bem como quais são os processos envolvidos na faculdade de conhecer (FINGER-KRATOCHVIL, 2010; CHAVES e LOPES, 2012). O aprendiz, conforme Barbeiro (2006, p. 3), "deve tomar consciência das estratégias que pode utilizar para a aprendizagem do vocabulário, tomando um papel activo na procura daquelas que se revelam mais eficazes para si". Bons leitores, normalmente, fazem uso dessas estratégias de forma inconsciente, pois as têm como parte de suas 
habilidades. Contudo, grande parte dos leitores menos proficientes precisa que elas lhes sejam ensinadas explicitamente a fim de que se tornem parte do repertório disponível de cada um e, à medida que usadas com frequência, venham a se tornarem habilidades de sua compreensão leitora.

A leitura é amplamente reconhecida como uma das habilidades mais importantes para o sucesso acadêmico, tanto em língua materna quanto estrangeira. Segundo Schmitt et al. (2011), diversos estudos têm identificado fatores que contribuem para o desenvolvimento das habilidades de leitura, e, sem dúvida, um dos principais é o conhecimento das palavras utilizadas no texto. As pesquisas têm confirmado o que os profissionais da educação há muito têm percebido, isto é, que o conhecimento de vocabulário e o desempenho de leitura apresentam-se fortemente correlacionados.

Considerando as questões discutidas anteriormente, leitores que têm um vocabulário reduzido apresentam maiores dificuldades na leitura, pois necessitam despender mais tempo e energia cognitiva para a realização da tarefa. Conforme apontam Morais, Leite e Kolinsky (2013), as lacunas no léxico mental (ortográfico, por exemplo) são fatores de dificuldade no processamento em leitura. Por serem mais lentos na leitura, tais indivíduos tendem a perder a conexão entre as partes do texto e, por consequência, apresentam dificuldades para chegar à macroestrutura. Ao chegarem ao final de um parágrafo, considerando os limites da memória de trabalho, podem se esquecer de seu início, necessitando, por isso, fazer frequentes releituras, retomadas do texto e/ou paradas para construir o significado das palavras, quebrando, assim, o fluxo da leitura.

\section{Estratégia de consulta ao dicionário}

No âmbito metacognitivo de desenvolvimento, as estratégias possibilitam ao leitor resolver um problema de conhecimento lexical com o qual se depare tornando-o mais proficiente e independente como aprendiz de vocabulário, em especial. As principais estratégias de aquisição lexical são: o uso do contexto, da morfologia e do dicionário. Quando as duas primeiras não dão conta de atender as necessidades de construção de significado da palavra, o leitor precisa avaliar se a palavra é crucial para sua compreensão do texto. Se for, ele precisará valer-se de uma fonte especializada como obras de referência e dicionários. Dentre as estratégias mencionadas, o dicionário tem sido sugerido como última estratégia a se recorrer, por ser a que mais demanda tempo e interrompe o fluxo de leitura. Por isso, antes de utilizá-lo, recomenda-se ao leitor avaliar o que não ficou claro, e qual a importância desse item lexical para construir um sentido para o texto. É importante destacar que a capacidade de avaliar adequadamente integra as habilidades metacognitivas, e se não estiver bem desenvolvida pode levar à chamada ilusão do saber. Ou seja, nesse caso, o leitor pode julgar, por exemplo, não ser necessária a consulta ao dicionário, e, ao final, ter sua compreensão prejudicada pelo desconhecimento da palavra.

O uso do dicionário e as releituras, apesar de tenderem a quebrar o fluxo, não são, em si, aspectos negativos para a leitura. Eles necessitam, contudo, ser executados nos momentos certos. A frequência dessas ações é que pode trazer prejuízos à compreensão leitora, devido à constante quebra do fluxo de leitura, fazendo com que aumente o grau de frustração do indivíduo e este desista de ler, acentuando assim seu empobrecimento lexical (FINGER-KRATOCHVIL, 2013; STANOVICH, 1986). Não obstante suas limitações, o dicionário, se utilizado com rapidez e eficiência, é uma habilidade básica de estudo que serve de apoio a todo o processo de ler para aprender (SOLÉ, 1998; ALLIENDE; CONDEMARÍN, 2005; XATARA; BEVILACQUA; HUMBLÉ, 2011). Finger-Kratochvil chama a atenção para o fato de que: 
Aprender a partir do dicionário requer considerável sofisticação. Interromper sua leitura para encontrar uma palavra não familiar em ordem alfabética, enquanto isso manter o contexto original em mente, de forma que você possa compará-lo com os sentidos dados no dicionário e, então, selecionar o sentido que é o mais apropriado ao contexto original - isso é uma tarefa cognitiva de alto nível (FINGER-KRATOCHVIL, 2013).

Quanto à sua contribuição para a construção do conhecimento lexical, a estratégia de uso do dicionário tem sido considerada a que menos gera dúvidas devido à sua confiabilidade. Ao recorrer a um dicionário os usuários, normalmente, o fazem para conhecer a grafia, o(s) significado(s) correto(s) de um item lexical, assim como seus possíveis usos ou acepções. Entretanto, grande parte das pessoas não sabe utilizar essa ferramenta de forma adequada por desconhecerem os tipos existentes, seu potencial e as informações que disponibilizam em sua plenitude. Outras encontram dificuldades em compreender certas definições contidas nos dicionários, mantendo-se sem o devido esclarecimento (FINGER-KRATOCHVIL, 2010; XATARA; BEVILACQUA e HUMBLÉ, 2011).

Leffa (2006, p. 322) previne que, por ser descontextualizada a informação lexical fornecida pelo dicionário, "é preciso contar com a capacidade do leitor em fazer interagir os dados do dicionário com os dados do texto e com o seu próprio conhecimento prévio para construir um sentido do texto". Ele ainda alerta que usar o dicionário como objeto de estudo é importante, porém, sempre integrado ao texto. E, por isso, cabe ao professor ensinar o estudante a não se desligar do texto no momento da consulta ao dicionário, realizando-a o mais rapidamente possível (LEFFA, 2011).

Em seu estudo sobre o uso do dicionário, com base nas pesquisas de Scholfield, Finger-Kratochvil (2010) afirma existirem cinco etapas necessárias ao processo de leitura para que o leitor se utilize dessa estratégia com eficácia. São elas: 1) perceber que está com dificuldade na compreensão total ou parcial de um determinado item lexical no contexto em que está inserido; 2) ter a iniciativa de consultar o dicionário; 3) encontrar a entrada que busca; 4) localizar a informação desejada e, finalmente, 5) explorar a informação conseguida sobre o significado da palavra, associando-a ao contexto do texto.

Nos últimos anos, pesquisas também vêm sendo realizadas com o objetivo de comparar os dicionários eletrônicos on-line e off-line aos dicionários impressos a fim de verificar qual deles responde melhor às demandas do leitor com relação ao conhecimento lexical. E entre elas estão as de Leffa (2006), Ebner e Ehri (2013) e de Min (2013). De acordo com este último, a utilização de tecnologias digitais, visando melhorar as competências lexicais, tais como os dicionários eletrônicos de mão, dicionários on-line, ou glossários eletrônicos também podem melhorar a eficácia do uso do dicionário. Menos tempo gasto e menos distrações para os leitores são alguns dos efeitos positivos quando se refere à pesquisa de palavras desconhecidas por meio de um link eletrônico.

Quando o enfoque está na construção do sentido do texto e, preferencialmente, se tem "a integração do texto com o dicionário, apresentando a palavra situada num contexto real de uso, não só amplia a ação do dicionário, mas também contribui para um processamento cognitivo mais profundo, provavelmente auxiliando na retenção da palavra" (LEFFA, 2006, p. 334), pois o dicionário eletrônico, segundo o autor, ajuda a diminuir a distância entre quem sabe menos de quem sabe mais. Além disso, apresenta outras vantagens, tais como: mobilidade, rapidez de acesso e consulta, facilidade de atualização, associação ao texto, além da possibilidade de uso de múltiplas linguagens em sua interface.

Em se tratando de desvantagens do dicionário eletrônico, as pesquisas apontam para duas questões. Uma delas diz respeito à possível consulta rápida e descontextualizada das palavras desconhecidas, o que dificulta ao 
indivíduo internalizar a palavra e recuperá-la posteriormente. Isso ocorre, em especial, por oferecer muitas informações. Outra questão refere-se a consultar apenas uma parte do verbete, o que pode ocasionar uma seleção equivocada do significado mais adequado ao texto (LEFFA, 1992; 2006; MOKHTAR, 2013). Embora, esse possa ser um risco inerente ao dicionário impresso também, caso o leitor não tenha desenvolvido as estratégias de forma proficiente.

Em relação ao dicionário impresso, a principal vantagem está relacionada à sua disponibilidade para a consulta, considerando que nem todas as pessoas possuem equipamentos eletrônicos - e.g. computador ou dispositivos móveis - para serem usados como suporte ao dicionário eletrônico, além da segurança que o dicionário impresso transmite a algumas pessoas, sobretudo às menos familiarizadas com as TICs. Entretanto, gradativamente, percebemos o crescimento do acesso aos meios eletrônicos, sem por ora podermos afirmar que isso levará ao seu uso para consultas que promovam a aprendizagem do léxico na leitura.

\section{Recorte deste estudo: quebra do fluxo de leitura em ambas as mídias e seus reflexos na compreensão leitora}

Por meio de uma pesquisa pré-experimental, de abordagem psicolinguística, investigamos possíveis contribuições do blog (mídia virtual) no processo de construção da competência leitora a partir do desenvolvimento da estratégia do uso do dicionário para aquisição do conhecimento lexical. A hipótese central era de que a recursividade e a facilidade de acesso às consultas oferecidas pela interface do blog favoreceriam a construção do conhecimento lexical nas tarefas de leitura, reduzindo o tempo necessário à consulta e, portanto, a quebra do fluxo de leitura, o que, consequentemente, facilitaria o processo de compreensão leitora.
Buscamos identificar em qual das mídias - virtual ou impressa - haveria menos tempo de quebra do fluxo de leitura devido às pausas para consulta ao(s) dicionário(s); se, de alguma maneira, essa(s) consulta(s) contribuíram para a compreensão leitora dos participantes e, ainda, qual delas traria maior a contribuição. Ao término das leituras em ambas as mídias, os participantes deveriam elaborar uma síntese do texto lido, que serviu como instrumento para verificar a compreensão textual. Para analisá-las, foram convidados três professores-avaliadores. Os critérios para avaliação foram: a fidedignidade do texto, que objetivou avaliar em que medida se poderia dar credibilidade à síntese escrita pelo participante, ao compará-la com o texto original ( 0 a 35 pontos); a presença e a pertinência das marcas de autoria na produção da síntese ( 0 a 10 pontos); a presença de indícios de que o participante conhece como se estrutura uma síntese e o que é relevante para o seu conteúdo ( 0 a 10 pontos); a qualidade do texto em termos de coesão e coerência textuais ( 0 a 20 pontos); a identificação da ideia central do texto original (0 a 15 pontos) e a presença de características linguísticas próprias da modalidade escrita, que deve ser privilegiada ( 0 a 10). As sínteses tinham como objetivo analisar a capacidade de recuperação e interpretação da informação, assim como a de reflexão/avaliação do texto lido, e avaliar se houve diferença nas capacidades demonstradas na comparação entre as duas mídias.

Participaram do estudo cinco professores de Língua Portuguesa de cinco escolas públicas de Educação Básica da rede estadual, da zona urbana do município de Chapecó, no período de 2013 a $2014^{3}$.

Os participantes tinham o seguinte perfil, na ocasião da pesquisa: a) P1 - entre 30 e 35 anos de idade, graduado em Letras Português/Espanhol, atuando como professor de Língua Portuguesa; b) P2 - entre 35 e 40 anos de idade, graduado em Letras Português/Inglês, atuando no serviço de apoio

3 Parecer consubstanciado CEP (UFFS): 423.157 - Aprovado em 08/10/2013. 
pedagógico escolar; c) P3 - entre 35 e 40 anos de idade; graduado em Letras Português/Inglês, atuando como docente de Língua Portuguesa e Língua Inglesa; d) P4 - entre 50 e 55 anos de idade, graduado em Letras Português, trabalhando como docente de Língua Portuguesa; e) P5 - entre 20 e 25 anos de idade, cursando o $8^{\text {o }}$ semestre de Letras Português/Espanhol, atuando como docente de Língua Portuguesa. A média de idade deles, portanto, foi de 36,5 anos, sendo quatro com formação completa na área de Letras Português, concluída há mais de cinco anos, atuando na docência.

A opção por professores de Língua Portuguesa de escolas de Educação Básica como participantes da pesquisa levou em consideração o fato de serem eles um dos principais mediadores na formação de leitores na escola.

\section{Blog experimental - Leitura na mídia virtual}

Para o experimento foi criado um blog na plataforma de hospedagem Blogger.com. 0 ambiente ficou disponível apenas para um participante de cada vez e sem acesso ao público externo à pesquisa. Em seu leiaute foram disponibilizados cinco links laterais, permitindo acesso a três dicionários eletrônicos (iDicionário Aulete, Michaelis e Antônimos e Sinônimos) e a dois dicionários digitalizados (Conceitual e Etimológico).

Foram incluídos outros recursos como: links para bibliotecas digitais, blogs, imagens e vídeos sobre leitura, que serviriam como distratores, direcionando casualmente a atenção para imagens, vídeos, sons etc., que não tinham relação direta com o texto lido. Essa inclusão visou deixar o blog o mais próximo possível da realidade da internet, em que várias linguagens competem (na tela do computador) pela atenção dos usuários. Assim, se verificaria também se a presença das diversas linguagens, geralmente presentes nos blogs, seria um fator de distração e de prejuízo para a compreensão leitora dos participantes ou não.
Na configuração metodológica, optamos pela utilização de dois tipos de TAPs (Protocolos Verbais), o de autorrevelação ou concorrente, que buscou obter dados durante a leitura, e o de auto-observação, após a leitura, na forma de entrevista retrospectiva, visando contrastar a percepção do leitor sobre sua leitura com a efetiva compreensão textual. A avaliação da compreensão foi realizada por meio dos dados do TAP de verbalização concorrente e da síntese produzida pelo participante ao final da leitura, uma vez que, no primeiro caso, a informação deve ser resgatada da memória de longo prazo e esse resgate pode acarretar sua interpretação pelo participante - enquanto na segunda, ela ainda está na memória de trabalho, e por isso, a princípio, ainda pode ser resgatada por via direta.

Os textos utilizados nos TAPs foram originalmente preparados para o trabalho de Finger-Kratochvil (2010), observando as mesmas unidades de fatiamento para a leitura e lembretes de pausas. Para sua execução, utilizamos o Protocolo de Pausa, por meio de pontos vermelhos foram colocados ao final de cada parágrafo, para auxiliar os participantes que tivessem mais dificuldades de lembrar-se de verbalizar seu raciocínio. De acordo com Tomich (2007), ao ver o ponto, o participante deve obrigatoriamente interromper a leitura e dizer o que lhe vier à cabeça sobre o parágrafo ou parte do texto selecionada pelo pesquisador.

\section{TAP - Autorrevelação (verbalização concorrente)}

Para esta etapa da pesquisa cada participante recebeu as instruções de procedimento, pode esclarecer dúvidas e passou por treino para se familiarizar com o ato de "pensar em voz alta", bem como entender como funcionaria o Protocolo de Pausa e a presença dos equipamentos de gravação. Em seguida, o texto impresso "Água de lastro" foi entregue ao leitor, que deveria realizar a tarefa de lê-lo e, logo após, realizar sua síntese. Solicitamos ao participante que, 
durante a leitura, quando, em qualquer ponto do texto houvesse interrupção do fluxo de leitura devido a algum pensamento ou dúvida que lhe ocorresse, o relatasse apontando suas razões, independentemente de ter chegado ao "asterisco", ainda que, nesse ponto a parada fosse indispensável.

0 registro dos TAPs foi feito por meio de gravação em áudio e vídeo para posterior transcrição. $\mathrm{O}$ vídeo objetivou capturar os movimentos de face, tronco, braços e mãos. Dessa maneira, se poderiam obter informações a respeito de outras condutas que não fossem capturadas pela voz ou pelos demais instrumentos. Esse registro foi feito com vistas a identificar possíveis pistas de como os participantes constroem seu conhecimento lexical por meio da estratégia de uso do dicionário e para verificar prováveis diferenças no uso dos recursos oferecidos por meio de cada mídia - virtual e impressa - para essa construção.

Para o texto do blog, além das orientações anteriores, explicamos também ao leitor como deveria proceder após a leitura do texto, visto que teria que: digitar sua síntese no campo de um formulário colocado logo abaixo do texto; no próximo campo seu código alfanumérico de participante e, por último, clicar no ícone "enviar". Em seguida, ele receberia uma mensagem de confirmação do envio da síntese para a análise. Além disso, ele foi informado de que, nas laterais do blog, havia à sua disposição 04 dicionários, dois eletrônicos e dois digitalizados, dos quais poderia utilizar-se sempre que julgasse necessário. Para observar o movimento do mouse, uma filmadora foi instalada de frente para a tela do computador, e outra câmera de vídeo (do celular) registrou a expressão facial do leitor/usuário do blog.

\section{TAP de Auto-observação (entrevista retrospectiva)}

O Protocolo Verbal de auto-observação foi preparado na forma de entrevista retrospectiva, e visou acrescentar informações supostamente não obtidas no TAP de autorrevelação, assim como comparar as impressões do leitor a respeito de seu desempenho de leitura com o demonstrado pelas verbalizações concorrentes.

A entrevista foi estruturada com base no modelo apresentado por Tomich (2007), acrescida de perguntas voltadas especificamente para o uso das estratégias de aquisição de conhecimento lexical. Ela continha 13 perguntas, sendo 08 voltadas para a estrutura e o nível de complexidade do texto de forma global, e 05 focadas em questões de densidade lexical e das estratégias mencionadas anteriormente. Também utilizamos registro em áudio e vídeo.

\section{Análise dos dados e resultados}

Nesta seção, esclarecemos como se deu a coleta e análise dos dados, e, na sequência os resultados do recorte aqui proposto. A partir dos vídeos e gravações de áudio dos participantes foram realizadas as transcrições, que constavam das verbalizações, pausas e, no teste do blog, do movimento do mouse na tela do computador, bem como os dados da entrevista retrospectiva e do tempo de execução das tarefas. Além disso, para auxiliar nas análises, contamos com informações sobre os hábitos de leitura, prestadas pelos participantes por meio de um questionário.

Nas análises, consideramos as medidas de tempo total de realização de leitura nas mídias levando em conta o tempo gasto para realizar a leitura, utilizando-se (ou não) da estratégia de consulta aos dicionários disponíveis no blog e no material impresso e o tempo de quebras de fluxo da leitura, para verificar os tempos utilizados pelo leitor para resolver a dificuldade do desconhecimento do item lexical. Isso nos permitiu comparar os percursos daqueles participantes que realizaram as mesmas tarefas, relacionando esses dados com outros, particulares às estratégias de cada um. Em suma, buscamos 
registrar nas transcrições o máximo de elementos considerados pertinentes de serem estudados. A análise final levou em conta esses dados, cruzados de forma a ter maior detalhamento nas ações e nas falas dos participantes. Portanto, analisamos a relação entre os participantes e a mídia, ou seja, de que forma cada um fez a leitura de cada texto e como se movimentou em cada um dos ambientes, papel ou tela, tendo lido textos do mesmo gênero e com densidade lexical e complexidades sintáticas comparáveis, em ambas as mídias. A seguir, passamos à discussão dos resultados da pesquisa propostos para este trabalho.

Com respeito ao uso dos dicionários na mídia virtual, observamos que somente um dos participantes utilizou-se de dois dicionários, Aulete e Michaelis on-line. Pela filmagem nos foi possível acompanhar a trajetória e a duração dos acessos. As imagens nos mostraram que o participante optou primeiro pelo dicionário que dispunha de um campo de pesquisa na tela do blog, para depois utilizar-se daquele que o redirecionava à outra página. Já os links colocados como distratores não foram selecionados em nenhum momento. Talvez, esse comportamento pudesse ter sido diferente, caso estivessem realizando uma navegação espontânea pelo blog.

A Tabela 1 mostra as medidas de tempo de realização da leitura e respectiva tarefa na mídia impressa, por participante e também a média geral, bem como o número de vezes que cada participante consultou o dicionário e, por fim, a medida de aceitabilidade de sua síntese. Esses elementos nos auxiliaram na análise do desempenho dos participantes.

Ao observamos os dados referentes à mídia impressa, percebemos, por meio das medidas de tempo, que os participantes P1, P2 e P3 e P5 apresentaram similaridade em relação aos tempos de leitura, considerando o tempo total empregado para a tarefa. Comportamento distinto, verificamos no tempo de P4, que apresentou o tempo mais longo do grupo. Em relação ao número médio de consultas ao dicionário $(2,66)$, aproximam-se apenas
P1, P2 e P3. Tanto P5 quanto P4 diferenciam-se da média e de forma oposta. Enquanto P5 faz apenas uma consulta, P4 faz 8. Contudo, o quesito com maior distinção e que nos possibilita observar a diferença desses elementos estudados relaciona-se à avaliação e à aceitabilidade das sínteses; ou seja, o resultado do processo de leitura executado de formas distintas. Observamos que P1, P2 e P3 obtiveram percentuais aproximados no quesito aceitabilidade; contudo, P4 e P5 caminharam, mais uma vez, para extremos opostos. A aceitabilidade da síntese de P5 indica que sua compreensão leitora foi a mais frágil, enquanto a de $\mathrm{P} 4$, a mais consolidada e proficiente. Diante dos dados, verificamos que P4 é o leitor que mais emprega tempo e esforços cognitivos para o processo de construção da compreensão leitora e seus resultados indicam que isso lhe foi positivo e efetivo.

Tabela 1 - Medidas de tempo individual e média geral - leitura na mídia impressa

\begin{tabular}{|c|c|c|c|c|c|c|}
\hline Participante & $\begin{array}{l}\text { Duração } \\
\text { Leitura } \\
\text { (min/seg) }\end{array}$ & $\begin{array}{l}\text { Duração } \\
\text { Síntese } \\
\text { (min/seg) }\end{array}$ & $\begin{array}{l}\text { Duração } \\
\text { Total } \\
\text { (min/seg) }\end{array}$ & $\begin{array}{l}\text { Consultas } \\
\text { Dicionário }\end{array}$ & $\begin{array}{l}\text { Duração } \\
\text { Consulta } \\
\text { (min/seg) }\end{array}$ & $\begin{array}{c}\text { Síntese- } \\
\text { Aceitabilidade } \\
\text { dos Avaliadores }\end{array}$ \\
\hline P1 & $11: 52$ & $21: 00$ & $32: 00$ & 2 & $\begin{array}{l}00: 14 ; \\
00: 16\end{array}$ & $54,6 \%$ \\
\hline P2 & $16: 05$ & 06:05 & $22: 20$ & 3 & $\begin{array}{l}00: 32 \\
00: 22 \\
00: 44\end{array}$ & $53,3 \%$ \\
\hline P3 & $14: 46$ & $12: 00$ & $26: 00$ & 3 & $\begin{array}{l}00: 24 \\
00: 38 \\
00: 58\end{array}$ & $66,6 \%$ \\
\hline P4 & $21: 30$ & $30: 00$ & $52: 00$ & 8 & $\begin{array}{l}00: 23 \\
00: 37 \\
01: 41 \\
00: 46 \\
00: 53 \\
01: 04 ; \\
01: 03 ; \\
01: 34\end{array}$ & $82,3 \%$ \\
\hline P5 & $12: 15$ & $14: 24$ & $26: 39$ & 1 & 01:19 & $15,6 \%$ \\
\hline Médias & $15: 10$ & $17: 05$ & $32: 10$ & 3,4 & $00: 47$ & $54,48 \%$ \\
\hline
\end{tabular}

Fonte: CARVALHO (2014). 
Estas informações parecem destacar o fato de que a interrupção intencional da leitura, caso de P4, por exemplo, para uso de uma estratégia de aquisição lexical, ainda que interfira no fluxo e despenda um pouco mais de tempo, possibilita uma melhor compreensão leitora. P4 reconhece isso ao ser questionado sobre o que facilitou sua compreensão: “[...] $O$ recorrer ao dicionário. Pra mim foi isso!". Em muitas situações, conforme Solé (1998) e Alliende e Condemarín (2005), faz-se necessária a interrupção da leitura para a consulta a uma fonte especializada, a fim de se construir o significado da palavra, para dar continuidade, com compreensão, à leitura do texto. Observação essa que parece não ter sido integrada ao modus operandi de P5, por exemplo, levando-o a resultados precarizados de compreensão. Ele menciona no TAP de auto-observação, justificando o fato de não utilizar-se do dicionário: “[...] Tentei identificar se aquela palavra era importante pra eu entender o contexto do parágrafo ou pra entender todo o texto. Na verdade isso é uma estratégia de diminuir tempo, né [...]". O participante assume uma fala a respeito do processo de ensino das estratégias de aquisição lexical do grupo de formação que fazia parte, sem contudo, demonstrar a internalização desses processos metacognitivos, considerando a sua ineficácia.

A Tabela 2 apresenta, em mesma disposição, dados relativos à mídia virtual. No cômputo geral, as médias de duração total e parciais da leitura e número de consultas aos dicionários disponíveis na mídia virtual são semelhantes às impressa. Até mesmo a avaliação da aceitabilidade das sínteses não apresenta diferenças de média geral, o que poderia nos levar a pensar que as mídias não exerçam grande influência nos resultados da compreensão leitora.

Ao focalizarmos o desempenho de cada participante, observando a mídia virtual, percebemos que o tempo empregado foi semelhante para P1, P2, P3. Eles demonstraram comportamentos semelhantes entre si também na mídia impressa. Novamente, quem nos chama atenção são P4
Tabela 2 - Medidas de tempo individual e média geral - leitura na mídia virtual

\begin{tabular}{ccccccc}
\hline Participante & $\begin{array}{c}\text { Duração } \\
\text { Leitura } \\
\text { (min/seg) }\end{array}$ & $\begin{array}{c}\text { Duração } \\
\text { Síntese } \\
\text { (min/seg) }\end{array}$ & $\begin{array}{c}\text { Duração } \\
\text { Total } \\
\text { (min/seg) }\end{array}$ & $\begin{array}{c}\text { Consultas } \\
\text { Dicionário }\end{array}$ & $\begin{array}{c}\text { Duração } \\
\text { Consulta } \\
\text { (min/seg) }\end{array}$ & $\begin{array}{c}\text { Síntese- } \\
\text { Aceitabilidade } \\
\text { dos Avaliadores }\end{array}$ \\
P1 & $06: 33$ & $21: 00$ & $27: 33$ & 1 & $00: 34$ & $62 \%$ \\
P2 & $14: 00$ & $06: 36$ & $20: 36$ & 2 & $\begin{array}{c}00: 33 ; \\
00: 17\end{array}$ & $43,6 \%$ \\
P3 & $13: 00$ & $14: 35$ & $27: 35$ & 2 & $\begin{array}{c}01: 34 ; \\
01: 30\end{array}$ & $57,3 \%$ \\
& & & & & $02: 02 ;$ & \\
P4 & $17: 42$ & $38: 00$ & $55: 00$ & 4 & $\begin{array}{c}00: 59 ; \\
00: 26 ;\end{array}$ & $72,7 \%$ \\
& & & & & $00: 31$ & \\
P5 & $24: 56$ & $12: 10$ & $37: 06$ & 1 & $01: 23$ & $11,3 \%$ \\
Médias & $15: 00$ & $18: 00$ & $33: 40$ & 2 & $00: 59$ & $49,38 \%$ \\
\hline
\end{tabular}

Fonte: CARVALHO (2014).

e P5. O primeiro, P4, por apresentar comparativamente o mesmo padrão de comportamento da impressa, i.e., emprego de maior tempo que os demais para a leitura e construção de sua síntese, maior número de consultas ao dicionário e melhor aceitabilidade da síntese, de acordo com os avaliadores. Observando apenas os dados do tempo, parece-nos estar diante de um leitor maduro e proficiente em Língua Portuguesa (L1) que, apesar da mídia, pautase em habilidades e estratégias construídas que lhe são confiáveis. Por outro lado, P5 apresenta emprego de tempo muito distinto individualmente e no grupo, quando comparado. Em primeiro lugar, seu tempo de leitura aumenta bastante, superando inclusive P4. Além disso, os demais participantes diminuem o tempo de leitura quando comparado à mídia impressa, sendo P5 o único não só a aumentar, como a superar as marcas de tempo em relação aos demais. Considerando que P5 era o participante mais jovem, havia a expectativa de certa familiaridade com as TICs e, portanto, menor desconhecimento no uso do blog, levando-nos, mais uma vez, a considerar que as fragilidades estão, em grande medida, relacionadas às suas habilidades de 
leitor e, consequentemente, à sua compreensão leitora, as quais acabam por interferir em qualquer tarefa ou mídia. 0 participante releva sua insegurança em relação à compreensão do texto ao mencionar no TAP de autorrevelação, após terminar a leitura: “Vou tentar fazer a síntese. [volta ao início do texto com o cursor] [pergunta para a pesquisadora] Eu só começo a fazer a síntese quando eu entendo todo o texto, ou...?’. Essa fala demonstra que P5 está incerto não só da tarefa, mas de preencher os requisitos para realizá-la. Um leitor proficiente tem uma consciência maior do processo de construção do sentido do texto sem necessariamente entender a compreensão como produto acabado.

Outro aspecto a destacar, em relação a P5, é o tempo para a construção da síntese que só não é menor que o de P2 - 12min. 10 e 06 min. 36, respectivamente. Esse dado parece ter seus reflexos na avaliação da aceitabilidade, pois são as duas com índices menores. Contudo, P5 apresenta o desempenho mais frágil. A avaliação de sua síntese indica um grau baixíssimo de compreensão leitora, apesar do tempo empregado para a leitura e construção da síntese que somados são superiores aos de P1, P2 e P3, indícios da existência de lacunas de base nas habilidades de leitura.

De forma geral, observando as médias apresentadas nas duas mídias, percebemos que o tempo médio de leitura foi em torno de 15 minutos. Além disso, o tempo despendido pelos leitores foi bastante semelhante para quase todas as tarefas. Isso parece demonstrar que o suporte, em si, não tem interferido para o processo de compreensão leitora.

\section{0 dicionário, as mídias e o processo de compreensão leitora: habilidades e estratégias}

Na seção anterior, observamos os tempos médios para a realização das tarefas em geral e da tarefa de leitura e síntese pelos participantes. Passamos agora a debater os tempos que envolvem o uso do dicionário e suas possíveis influências no processo de compreensão leitora na mídia impressa e na mídia virtual.

Conforme podemos observar na Tabela 1, ao considerarmos o número de consultas e o tempo despendido pelos participantes, na leitura em mídia impressa e, nessa etapa, dicionário impresso, o comportamento de $\mathrm{P} 4$ se destaca não só pelo número de consultas realizadas, i.e., mais que o dobro da média - 3,4, mas também pelo tempo empregado nas consultas. Em metade delas, o tempo de trabalho com o dicionário está acima da média dos participantes, ou seja, acima de 47 segundos. Das consultas realizadas por P1, P2 e P3, apenas a de P3 supera a média, ficando as demais abaixo. P1 possui os tempos mais curtos de consulta, não ultrapassando 18 segundos. P5 realiza uma consulta com o segundo tempo mais longo, $1 \mathrm{~min} 19 \mathrm{seg}$ Identificamos certa regularidade no uso do dicionário para três dos participantes - P1, P2, P3 - enquanto que P4 e P5 são sui generis, trabalhando nos extremos de um suposto contínuo.

Na mídia virtual, com exceção de P5 que manteve apenas uma consulta aos dicionários eletrônicos, igualando-se em número a seu comportamento anterior, percebemos mudanças a considerar, pois diminuem as consultas, i.e., 2, e aumenta o tempo médio utilizado quando comparado aos resultados da mídia impressa, i.e., 59seg, no geral. Em outras palavras, P1 e P2 apresentam tempos de consulta semelhantes que variam entre 17seg e 34seg; contudo, P3 aumenta os seus tempo de consulta - 01min34seg e 01min30seg - e P4, apresenta tempos muito diversos para a consulta.

A fim de melhor entender esses dados, nos será necessário observar, além do quantitativo, elementos do qualitativo, ou seja, os processos da consulta e de leitura, registrados pelos TAPs e declarações obtidas nos relatos retrospectivos, somando esse olhar ao dado temporal. Percebemos que o tempo médio aumentou nessa mídia, enquanto decresceu o número de consultas. Os dados dos TAPs nos revelam que os tempos mais curtos 
ocorreram quando a circulação entre dicionário (em consulta) e texto se passaram sem estranhamento ou perda dos espaços virtuais, i.e., dicionário e texto em processo de compreensão. Quando os tempos excederam $1 \mathrm{~min}$, observando o processo, deflagramos a existência de algum tipo de problema, seja de habilidade com o ambiente virtual disponibilizado para a leitura, seja de consulta. De acordo com relatos na entrevista retrospectiva, os participantes declararam dificuldades para transitar entre os espaços e dar continuidade ao trabalho de compreensão, gerando, por sua vez, uma interrupção de tempo de leitura maior que a desejada e, portanto, uma demanda cognitiva maior para a compreensão.

Observando as opções de consulta utilizadas, dentre os dicionários possíveis, o dicionário eletrônico Aulete teve superioridade, lembrando que disponibilizava um campo para pesquisa na página do blog. Além desse e-dicionário, somente o Dicionário Michaelis foi utilizado por dois dos participantes como segunda opção de consulta. Esse se apresentava para acesso a partir de uma imagem icônica da capa do dicionário utilizado na leitura na mídia impressa, fato que parece ter influenciado pela familiaridade com o ícone. Os demais - dicionários de sinônimos e antônimos, o conceitual e o etimológico - foram ignorados. Contudo, importa-nos chamar a atenção que esses dicionários estavam no topo da página, do lado direito; o que, aparentemente, pode ter sido um fator indutor da escolha. Os demais foram ignorados pelos leitores participantes.

Considerando as observações dos participantes, na entrevista retrospectiva, podemos atribuir as diferenças de uso observadas, entre os dicionários eletrônicos presentes no blog e o dicionário impresso, à diferença na praticidade e rapidez do dicionário eletrônico em relação ao impresso. Além disso, de acordo com seus relatos, o que dificultou a utilização, de forma mais ampla, foi a falta de habilidade deles com a navegação no ambiente virtual proposto, pois afirmaram estar familiarizados com sites de busca (por ex., o Google) e não blogs e dicionários especificamente, os quais apresentam diferenças formais e funcionais. Esse aspecto parece apontar para a falta de orientação e preparo no uso da mídia virtual voltada para a aprendizagem, i.e., para além do entretenimento. Nesse sentido, percebemos, sim, uma limitação para a construção da compreensão leitora, pois ao não poder se apropriar dos recursos disponíveis, utilizando-os estrategicamente, o leitor perde qualitativamente no processo e no produto.

As consultas ao dicionário, conforme destacamos, fazem parte do conjunto de estratégias de construção do conhecimento lexical e, normalmente, as de maior custo cognitivo para o leitor. Dentre os participantes, alguns consideram que a interrupção da leitura para a consulta pode ser prejudicial para a compreensão e por isso a evitaram, enquanto outros a avaliaram como importante e necessária. Os dados parecem revelar que, embora o empenho cognitivo seja maior, também o são seus benefícios, pois o participante com maior número de consultas (P4), tanto na mídia impressa como na virtual, e que despendeu o maior tempo para realizar as tarefas de leitura e escrita, foi o que obteve os melhores percentuais de aceitabilidade das sínteses. Do outro lado, aquele que realizou menos consultas, demonstrou-se preocupado com o tempo, apresentou as maiores fragilidades nos resultados de compreensão leitora. Dessa forma, as quebras de fluxo de leitura, que, a princípio, podem ser vistas como negativas, diante da interrupção que ocasionam, para o fluxo da leitura e construção do sentido do texto, corroborando trabalho anterior, nem sempre podem ser entendidas como prejudiciais à compreensão leitora (FINGER-KRATOCHVIL, 2013).

\section{Considerações finais}

Com base na perspectiva psicolinguística, nosso intento foi nos aproximar dos processos de construção da competência lexical (estratégia 
metalinguística) dos participantes desta pesquisa para verificar possíveis contribuições do dicionário, tendo em vista sua amplitude de oferta em número e propósitos, por meio do blog (mídia virtual) para a compreensão leitora.

A hipótese primária era de que a multiplicidade de recursos e a facilidade de acesso às consultas ao dicionário oferecidas pelo blog estimulariam o uso do dicionário, quando comparado o processo de leitura na mídia impressa. Isso, por sua vez, favoreceria a construção de habilidades da competência lexical, por diminuir o tempo de quebra de fluxo de leitura, e longo prazo, consequentemente, colaboraria para uma melhor compreensão leitora.

Como resultado de nossas análises, constatamos que não houve uma diferença considerável no tempo de leitura entre as duas mídias, e que houve menos consultas ao dicionário no blog, com duração maior do que ao dicionário impresso. A pequena diferença revelada, quanto ao percentual de compreensão leitora entre uma mídia e outra, pode indicar não haver considerável diferença entre elas no uso das estratégias de aquisição lexical, e especialmente, do dicionário, seja ele eletrônico ou impresso, se não houver, conforme Ribeiro (2008), uma boa complementaridade entre habilidades de leitura e de navegação na internet, além de o suporte virtual apresentar algumas singularidades que, a princípio, tendem a estranheza ao leitor mais adaptado à leitura no material impresso (WÄSTLUND, 2007). $O$ fator mais relevante apontado pelos resultados foi a capacidade demonstrada pelo leitor maduro e proficiente, portanto, consciente de muitas estratégias, de se utilizar do conhecimento condicional - i.e., quando e para quê - para selecionar a estratégia mais adequada para a situação.

Como o número de participantes da pesquisa foi pequeno, não nos sentimos à vontade para fazer afirmações sem a análise de uma amostra maior. Inclusive porque, como afirma Creswell (2007), em se tratando de pesquisa com seres humanos, o pesquisador deve ter cautela ao pretender "provar" causa e efeito, devido à complexa multidimensionalidade da natureza humana. $\mathrm{O}$ que podemos por ora afirmar é que sem as devidas habilidades de uso do computador, de navegação e uso dos recursos disponíveis na web, não há diferença considerável de aprendizado para melhor, já que o uso inadequado ou limitado dos recursos pode, pelo contrário, interferir negativamente na aprendizagem do conteúdo proposto. Fato esse corroborado pelos participantes na entrevista retrospectiva (TAP de auto-observação).

No desenvolvimento deste estudo, deparamo-nos com algumas questões que podem vir a gerar temas para novas pesquisas na área. Algumas delas seriam: a) a verificação de uma fragilidade na proposta de elaboração de uma síntese para verificar a compreensão leitora, que pode ter interferido em sua demonstração, levando-se em consideração que a escrita exige outras habilidades que não estavam sendo consideradas no estudo, embora esse assunto não encontre defesa unânime na literatura (KINTSCH; RAWSON, 2005); b) a diferença entre os participantes, com respeito a suas habilidades de navegação na internet, especialmente com o objetivo de ler para aprender e; c) a diferença considerável de faixa etária entre alguns participantes, gerando diferenças significativas de conhecimento e maturidade para as tarefas.

Não almejamos, obviamente, generalizar os resultados a que chegamos. Contudo, acreditamos ser interessante replicar este estudo com um número maior de participantes como primeiro ponto e, além disso, observar outras variáveis que possam esclarecer melhor as diferenças de resultados obtidos nesse trabalho. Em outras palavras, será importante observar e controlar as habilidades de navegação na internet, bem como as faixas etárias, e até mesmo os conhecimentos metacognitivo. Dessa forma, poderemos complementar o entendimento de possíveis perguntas que ainda nos fazemos em relação a este estudo e ao tema que entendemos ser precioso para as novas gerações. 


\section{Referências}

AGUILERA, María Cristina Arancibia. Estrategias de comprensión con hipertexto informativo. Lectura y vida - revista latinoamericana de lectura, v. 31, n. 2, p. 18-32, 2010. ALLIENDE, Felipe. CONDEMARÍN, Mabel. A leitura: teoria, avaliação e desenvolvimento. Porto Alegre: Artmed, 2005.

BAKER, Linda; BROWN, Ann L. Metacognitive skills and reading. In: PEARSON, P. D. (Ed.). Handbook of research on reading. New York: Longman, 1984.

BARBEIRO. Luís Filipe. Vocabulário_quadro_geral. Projecto Diversidade Linguística na Escola Portuguesa. Disponível em: <http://www.iltec.pt/divling/_pdfs/cd2_vocabulario_ quadro-geral.pdf>. Acesso em: 23 nov. 2013.

BAUMANN, James F.; KAME'ENUI, Edward J.; ASH, Gwynne E. Research on vocabulary instruction: Voltaire redux. Handbook of research on teaching the English language arts, v. 2, p. 752-785, 2003.

CARVALHO, Margarete Gonçalves Macedo de. Leitura e mídia virtual: a construção da competência lexical através do blog. Dissertação (Mestrado em Estudos Linguísticos) Programa de Pós-graduação em Estudos Linguísticos, Universidade Federal da Fronteira Sul, Chapecó, 2014

CASSANY, Daniel. Explorando las necesidades actuales de comprensión. Aproximaciones a la comprensión crítica. Lectura y vida, v. 25, n. 2, p. 6-23, 2004.

CHAVES, Jésura; LOPES, Marília. Metacognição e Metalinguagem. In: PEREIRA, V. W.; GUARESI, Ronei (Orgs). Estudos sobre leitura: psicolinguística e interfaces. Porto Alegre: ediPUCRS. 2012, p. 21-30.

COSCARELLI, Carla V.; NOVAIS, Ana Elisa. Leitura: um processo cada vez mais complexo. Letras de Hoje, Porto Alegre, v. 45, n. 3, p. 35-42, jul.-set. 2010.

CRESWELL, John W. Projeto de pesquisa: métodos qualitativo, quantitativo e misto. 2. ed. Porto Alegre: Artmed, 2007.

EBNER, Rachel J.; EHRI, Linnea C. Vocabulary Learning on the Internet: Using a Structured Think - Aloud Procedure. Journal of Adolescent \& Adult Literacy, v. 56, n. 6, p. 480-489, 2013.

FARSTRUP, Alan E.; SAMUELS, S. Jay. Vocabulary instruction: a critical component for skillful reading. In: FARSTRUP, Alan E.; SAMUELS, S. Jay. What research has to say about vocabulary instruction. International Reading Assoc., p.1-5, 2008.
FINGER-KRATOCHVIL, Claudia. Estratégias para o desenvolvimento da competência lexical: relações com a compreensão em leitura. Tese (Doutorado em Letras) - Programa de Pós-graduação em Letras, Universidade Federal de Santa Catarina, Florianópolis, 2010

O aprendiz estratégico e crítico na era da informação. In: DIAS, Antônio HETKOWSKI, Tânia M. (Org.). Educação e Contemporaneidade: pesquisas científicas e tecnológicas. Salvador: Editora da Universidade Federal da Bahia - EDUFBA, 2009. v. 1, p. 203-229.

GOLDMAN, Susan et al. Comprehending and Learning From Internet Sources: Processing Patterns of Better and Poorer Learners. Reading Research Quarterly, Illinois, 2012. Disponível em: <http://onlinelibrary.wiley.com/doi/10.1002/RRQ.027/abstract>. Acesso em: 03 set. 2013

KINTSCH, Walter; RAWSON, Katherine E. Comprehension. In: SNOWLING, Margaret J.; HULME, Charles (Ed.). The science of reading: a handbook. [S.I.]: John Wiley \& Sons, 2005. p. 71-92.

LEFFA, Vilson J. Aspectos da leitura. Uma perspectiva psicolinguística. Porto Alegre. Sagra-Luzzatto. 1996.

Reading with an electronic glossary. Computers \& Education, Great Britain, v. 19 n. 3, p. 285-290, 1992

. O dicionário eletrônico na construção do sentido em língua estrangeira. Cadernos de tradução, Florianópolis, n. 18, p. 319-340, 2006

. Questões de lexicografia pedagógica. In: XATARA, C., BEVILACQUA, Cleci Regina \& HUMBLÉ, Philippe René Marie (Orgs.). Dicionários na teoria e na prática: como e para quem são feitos. São Paulo: Parábola Editorial, 2011. p. 123-132.

MIN, Young- Kyung. Vocabulary Acquisition: Practical Strategies for ESL Students. Journal of International Students, v. 3, n. 1, Spring 2013. Disponível em: <http://jistudents.files. wordpress.com/2012/07/8-young-updated.pdf>. Acesso em: 23 nov. 2013.

MOKHAR, Ahmad Azman. The Role of Dictionary Strategy in Passive Vocabulary Knowledge Acquisition of Net Generation Students. Journal for the Study of English Linguistics, v. 1, n. 1, 2013. Disponível em: <http://www.macrothink.org/journal/index.php/jsel/article/ view/4444>. Acesso em: 23 nov. 2013

MORAIS, José; LEITE, Isabel; KOLINSKY, Régine. Entre a pré-leitura e a leitura hábil: Condições e patamares da aprendizagem. In: MALUF, Maria Regina; CARDOSO-MARTINS, 
Cláudia. Alfabetização no século XXI: Como se aprende a ler e a escrever. Penso Editora, p. $17-48,2013$

NAGY, William E.; HERMAN, Patricia A. Breadth and depth of vocabulary knowledge: Implications for acquisition and instruction. The nature of vocabulary acquisition, v. 19, p. 35, 1987.

NAGY, William E.; SCOTT, Judith A. Vocabulary processes. In: ALVERMANN, Donna E.; UNRAU, Norman J.; RUDDELL, Robert B. Theoretical models and processes of reading. International Reading Assoc., p. 458-488, 2013. (Publicado originalmente in: KAMIL, M. et al. Handbook of reading research. Mahwah: Lavrence Erlbaum, 2000. v. 3, p. 269-284).

NASCIMENTO, Tânia Augusto et al. Fluência e compreensão leitora em escolares com dificuldades de leitura. Rev Soc Bras Fonoaudiol, v. 23, n. 4, p. 335-43, 2011.

PEREIRA, Vera Wannamacher. Compreensão leitora de alunos do ensino médio. Revista Virtual de Estudos da Linguagem, v. 6, n. 11, p. 1-15, 2008.

PERINI, Mario A. Efeito do gênero textual. In: LIBERATO, Yara; FULGENCIO Lúcia. É possível facilitar a leitura: um guia para escrever claro. São Paulo: Contexto. 2012. p. 152-158.

RANGEL, Egon de Oliveira. Dicionários em sala de aula. Brasília: Ministério da Educação, Secretaria de Educação Básica, 2006.

RIBEIRO, Ana Elisa. Leitura nas interfaces gráficas de computador: compreendendo a gramática da interface. Dissertação (Mestrado em Estudos Linguísticos) - Programa de Pós-graduação em Estudos Linguísticos, Universidade Federal de Minas Gerais, Belo Horizonte, 2008.

RIBEIRO, Vera Masagão. Analfabetismo e analfabetismo funcional no Brasil. In: SANTOS, Emerson. Reescrevendo a Educação. São Paulo: Scipione, , 2006. p. 26-37.

SCHMITT, N. etal. The percentage of words known in a textand reading comprehension. The Modern Language Journal, v. 95, p. 26-43. 2011. Doi: 10.1111/j.1540-4781.2011.01146.x

SCLIAR-CABRAL, Leonor. Sistema Scliar de Alfabetização. Livro dos alunos: Aventuras de Vivi, 2012.

SOLÉ, I. Estratégias de leitura. Porto alegre: Artmed, 1998.

STANOVICH, Keith E. Matthew effects in reading: Some consequences of individual differences in the acquisition of literacy. Reading Research Quarterly, p. 360-407, 1986.

TOMITCH, Lêda Maria Braga (Org.). Aspectos cognitivos e instrucionais da leitura. São Paulo: EDUSC, 2008.
TOMITCH, Lêda Maria Braga. Desvelando o processo de compreensão leitora: protocolos verbais na pesquisa em leitura. [S.l.]: Signo, 2007. Disponível em: <https://online.unisc br/seer/index.php/signo/article/viewFile/244/197>. Acesso em: 20 nov. 2013.

WÄSTLUND, Erik. Experimental studies of human-computer interaction: working memory and mental workload in complex cognition. Karlstad, Sweden: Dept. of Psychology, Karlstad University, 2007.

XATARA, Cláudia M.; BEVILACQUA, Cleci R.; HUMBLÉ, Philippe, R. M. (Org.). Dicionários na teoria e na prática: como e para quem são feitos. São Paulo: Parábola Editorial, 2011.

Recebido em 25/04/2016. Aceito em 07/06/2016. 